\title{
The Importance of Perceived University-Life Balance, Hours Per Week Engaged in Academic Activities, and Academic Resourcefulness
}

\section{ABSTRACT}

The University Life Experience Inventory was created to determine how students utilize their time between academic (class and preparatory) and nonacademic (work, social, leisure, and health) activities. In addition to completing the university life experience inventory, 239 undergraduate students completed inventories assessing academic resourcefulness, academic self-efficacy, and university adaptation and satisfaction, along with single item questions asking about perceived academic/nonacademic balance and commitment to completing one's degree. Results indicated that total number of hours spent per week in various nonacademic activities was unrelated to most of the variables including academic hours, whereas the number of hours spent per week in academic activities was positively associated with the psychosocial variables and a unique predictor of academic resourcefulness and cumulative grades. Moreover, academic resourcefulness was observed to moderate the relationship between perceived balance and academic hours, such that the average number of hours spent engaged in academic activities per week was greater for students scoring high in academic resourcefulness regardless of whether they had low or high perceptions of balance, especially compared to those students who scored low in both academic resourcefulness and perceived balance. The results suggest that teaching students requisite academic resourcefulness skills to deal with academic challenges will assist them in increasing focus on their academic studies as opposed to nonacademic activities.

\section{KEYWORDS}

academic resourcefulness, grades, university adaptation, balance perceptions

\section{INTRODUCTION}

Most students engage in a wide variety of nonacademic activities while attending postsecondary education, including employment (Dundes \& Marx, 2006) extracurricular (Strapp \& Frarr, 2010), social (Buote et al., 2007), leisure (Mokhtari, Reichard, \& Gardner, 2009), and health related (American College Health Association, 2016; Gilbert \& Weaver, 2010) activities. Relatively unknown, however, is whether students' perceptions of being able to balance academic and nonacademic activities are associated with the hours they dedicate each week to such endeavors. A recent study found positive relationships between students' answer to one question regarding how well they thought they balanced their academic and nonacademic activities and their grades and university adaptation (Reed \& Kennett, 
2017). The current investigation aimed to determine if perceived balance, along with other variables known to be salient predictors of adjustment and performance (i.e., general and academic resourcefulness, and academic self-efficacy), were related to hours spent weekly in academic and nonacademic (social, work for pay, leisure, and health) tasks.

Researchers have examined the amount of time performing specific types of nonacademic activities and its impact on grades, retention, and university satisfaction. For example, it has been observed that students who are employed between 10 to 19 hours per week were more likely to attain higher grades compared to students who were employed for less or more hours (Dundes \& Marx, 2006; Holmes, 2008; Galbraith \& Merrill, 2015; Hovdhaugen, 2015), suggesting that working some hours forces students to manage their time more effectively. Working 20 or more hours per week has also been associated with higher dropout rates (Hovdhaugen, 2015). Similarly, Bergen-Cico and Viscomi (2012) found that students who attended between 5-14 university co-curricular events over the course of eight semesters had significantly higher grade point averages than did those who attended fewer or more events. Other researchers have reported that the number of hours dedicated to community-based, nonpaid, social activities (Stuart, Lido, Morgan, Solomon, \& May, 2011) and university-run activities (Strapp \& Farr, 2009) predicted higher levels of university satisfaction. Hours of sleep is also important, with studies finding that students who slept more hours and/or had a better quality of sleep were more likely to receive higher year-end grades (e.g., Gilbert \& Weaver, 2010). In contrast, certain leisure activities, such as the number of hours spent playing video games, has been found to be negatively associated with college students' grade point average (Anand, 2007). These investigations suggest that spending some time in certain types of nonacademic activities (e.g., employment, social, and health) can promote university success and satisfaction.

It is widely understood that to do well academically, it is essential for students to be academically resourceful and to have efficacious beliefs about their academic abilities. Relatively unknown, however, is if more time spent on academic endeavors is associated with higher academic resourcefulness skills and self-efficacy. Students scoring high in academic resourcefulness have a set of coping skills that allow them to manage academic challenges. These coping skills include the reliance on positive self-talk to calm discomforting thoughts, use of problem solving strategies to overcome anticipated and encountered academic setbacks, acknowledgement of the importance of effort in completing academic tasks and meeting deadlines, and ability to stay steadfast on difficult academic activities in lieu of engaging in more enjoyable events (Kennett, 1994). Studies have consistently found that greater use of these academic self-regulatory skills are uniquely related to higher grades and adjustment/retention when tested with other variables (e.g., Kennett, 1994; Kennett \& Keefer, 2006, Kennett \& Reed, 2009; Xuereb 2015). Xuereb (2015), for example, examined if academic resourcefulness and global coping responses to everyday stress predicted the likelihood of a student seriously considering dropping out of university (i.e., doubting) and observed that lower academic resourcefulness was the only significant predictor of doubt. In another study (Kennett \& Keefer, 2006), academic resourcefulness and selfefficacy were direct and positive predictors of grades, although greater general learned resourcefulness and attributing failure more to bad luck, and less to lack of ability and lack of effort also predicted yearend grades at the bivariate level. General resourcefulness refers to the acquired self-regulatory strategies needed to deal with day-to-day upsets (Rosenbaum, 1980, 1990) and includes similar content areas as academic resourcefulness, whereas academic self-efficacy refers to students' beliefs in their academic 
abilities. Other studies find academic resourcefulness, along with general resourcefulness and academic self-efficacy, to be positive and unique predictors of university adaptation (Martin \& Kennett, 2017).

Two of the most important and consistently unique predictors of academic resourcefulness is higher general resourcefulness and academic self-efficacy scores (e.g., Kennett, 1994; Kennett \& Keefer, 2006; Kennett \& Reed, 2009). To what extent these psychosocial variables are related to the time spent on academic and nonacademic tasks, however, is unknown and a query of the current investigation.

University students' perceptions of being able to balance academic and nonacademic activities has not been extensively studied. One of the first investigations asked graduate students in the United Kingdom if they felt a sense of balance between their work, study, and personal lives, and what strategies they used to maintain balance in their lives (Lowe \& Gayle, 2007). It was found that students who received personal and financial support believed they were balancing their life well. Just over 30 percent of students equally valued their job and academic studies, and over half of the graduate students thought that they had a good or manageable balance between their work, academic, and personal lives. No significant relationships, however, were found between characteristics of their work, personal, and academic lives, and their perceived level of balance. Though this study provides some insight on perceptions of balance, the responsibilities of a graduate student is far different from that of a typical undergraduate, with 40 percent of Lowe and Gayle's sample living with a spouse or partner and one third of them having children (Lowe \& Gayle, 2007).

Focusing solely on undergraduates, Reed and Kennett (2017) examined the influence of perceived academic and nonacademic balance between students with and without disabilities. Importantly, they also measured students' academic resourcefulness, academic self-efficacy, and adjustment to university. It was observed that students with disabilities had greater difficulty balancing academic and nonacademic activities than students without disabilities, perhaps because often these students have to spend extra time seeking, advocating for, and participating in accommodations for learning. Also, self-efficacy, academic resourcefulness, and academic adjustment were all positively related to the perceived ability to balance for both groups. Nevertheless, a moderating analysis revealed that the relationship between perceived ability to balance and adjustment to university was much stronger for students with disabilities than students without, such that low perceptions of balance for this former group was associated with the lowest university adaptation scores. Finally, greater perceived balance moderately predicted higher grades of students without disabilities. Although this study is one of the first to examine the importance of perceived balance on university adjustment and academic performance in undergraduate students, further research examining the number of hours that students spend engaged in various activities and its relationship to balance perceptions is warranted.

The current investigation asked students to report the number of hours they typically spend each week engaged in academic and various nonacademic activities, including work for pay, social, leisure, and health. Intuitively, it was hypothesized that students dedicating more time to their academic studies would score higher in general and academic resourcefulness, be more academically efficacious, attain higher grades, and be better adjusted to the university environment. Based on previous findings (Bergen-Cico \& Viscomi, 2012; Dundes \& Marx, 2006; Hovdhaugen, 2015), the opposite was predicted for greater hours spent on nonacademic activities, especially if the time spent particularly on employment and social activities exceeded 20 hours per week. To what extent perceptions of balance were related to actual hours spent engaging in academic endeavors was also explored, along with to what 
extent this relationship changes as a function of academic resourcefulness (i.e., students' use of academic coping skills). It was reasoned, for example, that low perceptions of balance would be associated with the lowest time spent in academic related activities, especially for students utilizing a limited repertoire of academic resourcefulness skills to manage their studies.

\section{METHOD}

\section{Participants}

A total of 239 students participated in this study, having a mean age of 20.23 years $(S D=4.65)$. Most participants were female (91 percent), full-time students (96 percent), single without children ( 89 percent), in their first (72 percent) or second ( 21 percent) year of study, non-psychology majors or undecided (71 percent), Canadian citizens (96 percent), Caucasian ( 80 percent), not living with parents ( 77 percent), and not registered with disability services ( 86 percent). For 42 percent of participants, their education was paid for by their family, 33 percent through student loans, 17 percent by self, and 7 percent by other means such as a scholarship.

\section{Procedure}

A convenience sample of undergraduate students was recruited during the second term of the academic year using an internal university online research participant management system (SONA), whereby interested students were redirected to an external online survey site (Qualtrics). After consent was obtained, the background information form was presented first followed by the questionnaires, which were presented in a random order. Once the survey was completed, participants were provided feedback and links to a variety of different academic, health, and counseling services that were available on campus and received a bonus credit towards an introductory psychology course. This study received ethical approval from the university's research ethics board.

\section{Measures}

Background information asked about students' age, gender, year of study, living arrangements, if they received any accommodations from the student accessibility services, ability to balance academic and nonacademic activities (using 5-point scale, with 1 being not well at all and 5 being extremely well), and sleep quality during the past month (with 1 being very bad to 4 being very good). Although students were asked to report their letter grades $(\mathrm{F}$ to $\mathrm{A}+$ ) from last semester and expected year-end letter grade ( $\mathrm{F}$ to $\mathrm{A}+$ ), actual cumulative credits and percent grade average were attained from students' records.

Rosenbaum's (1980) Self-Control Schedule assesses general resourcefulness and includes the following four content areas: the use of cognitions and positive self-instruction to cope with discomforting thoughts (e.g., "When I have to do something that makes me anxious, I try to visualize how I will overcome my anxiety while doing it."), the application of problem-solving strategies (e.g., "When I am faced with a difficult problem, I try to approach it in a systematic way."), the ability to delay gratification (e.g., "I prefer to finish a job that I have to do before I start doing things I really like."), and the recognition that self-changes require a lot of effort (e.g., "If I carried the pills with me, I would take a tranquilliser whenever I felt tense and nervous." - reverse-scored). The schedule consists of 36 items rated on a 6-point Likert scale $(-3=$ very uncharacteristic of $m e$, to $+3=$ very characteristic of $m e)$. Scores can range from -108 to 108 . Higher scores indicate higher general resourcefulness. Evidence for 
the construct-related validity and reliability of the Self-Control Schedule have been well documented (e.g., Boonpongmanee, Zauszniewski, \& Boonpongmanee, 2002; Ngai, Chan, \& Holroyd, 2008; Redden, Tucker, \& Leslie, 1983; Rosenbaum, 1980). Cronbach's alpha for the 36 Self-Control Schedule items in the current study was .85 .

Kennett's (1994) Academic Resourcefulness Inventory measures academic self-regulatory behaviours and consists of 23 items on a 7-point Likert scale, with contrasting statements at each end. The inventory specifically looks at students' ability to apply problem strategies to cope with the academic demands (e.g., "Organized versus Disorganized with my work."), use positive self-statements to deal with emotional upsets (e.g., "Self-assured versus Unassured when taking an exam/test."), and to delay avoidance by meeting deadlines for papers and assignments (e.g., "Infrequently versus Frequently requesting extensions."). Scores can range from 26 to 161, with higher scores indicating higher academic resourcefulness. Construct-related validity and internal consistency of the Academic Resourcefulness Inventory have been well established (e.g., Kennett, 1994; Kennett \& Keefer, 2006; Reed \& Kennett, 2017). Kennett (1994) found a 7-month test-retest reliability of .75. Internal consistency was high in the current study (23 items; a $=.88)$.

Kennett's (1994) 9-item Academic Self-Efficacy Scale measures students' beliefs about their academic abilities (e.g., "I expect to do well") using a 6-point Likert scale, ranging from 1 (strongly agree) to 6 (strongly disagree). Scores can range from 9 to 54, with higher scores indicating higher academic self-efficacy. Kennett (1994) demonstrated internal reliability, construct validity, and a 7month test-retest reliability of .75 . In the present study, internal reliability was excellent ( 9 items; $\mathrm{a}=$ $.93)$.

Crombag's (1968) 18-item University Adaptation Questionnaire assesses students' overall adjustment to university (e.g., "I am very satisfied with the course of my studies" and "I made many friends here"). Items are rated on a 6-point Likert scale with 1 being very uncharacteristic of me to 6 being very characteristic of me. Scores can range from 18 to 108, with higher scores reflecting greater adjustment to university. Van Rooijen's (1986) study supported internal consistency of the items (18 items; a = .83). In the current study, Cronbach's alpha was .90.

University Student's Motivation \& Satisfaction Questionnaire was used to assess students' university satisfaction and commitment to completing their degree (Neill, 2004). Student satisfaction items ask students about their satisfaction with available services (e.g., "student support services"), university facilities (e.g., "lecture theatres, tutorial rooms \& laboratory facilities"), social opportunities (e.g., "opportunities to make friends"), and quality of the teaching received (e.g., "level of knowledge of the staff who teach me"). The 19 items are rated on a 5-point Likert scale, ranging from 1 (very dissatisfied) to 5 (very satisfied). Scores can range from 19 to 95 , with higher scores reflecting a higher level of satisfaction. In the current study, Cronbach's alpha was .93. Students' commitment to completing their degree is assessed with a one-item question ("How likely is it that you will complete your current degree"), on a 7-point Likert scale ranging from 1 (definitely will not finish) to 7 (definitely will finish).

The University-Life Experience Inventory was created to assess the typical number of hours per week students spend engaging in academic and nonacademic activities and features the following eight items: 
a) attending class

b) preparing for class (studying, reading, writing, preparing presentations, etc.)

c) working for pay

d) participating in social activities within the university (clubs, organizations, sports, special lectures, social gatherings, etc.)

e) participating in social activities outside the university (social gatherings, family activities, community volunteering, religious services, etc.)

f) participating in leisure activities (watching television, playing video games, surfing the internet, reading for pleasure, listening to music, cooking, cleaning, shopping, etc.)

g) times per week engaging in at least 30 minutes of moderate- to high-intensity-levels of physical activity (walking, yoga, water aerobics/aerobics, gardening, pushing lawn mower, shoveling light snow, running, sports, etc.)

h) hours per night sleeping

Participants are informed at the beginning of the survey that there are a total of 168 hours in a week. For the first six activities, participants select one of the hour-range categories of 0, 1-5, 6-10, 1115, $16-20$, and $>20$, representing the typical number of hours they spend engaging in that activity per week and based on their selection are given a score of $0,5,10,15,20$, or 25 hours. Exercise receives a score of one hour times the number of days per week they report typically engaging in this activity. Similarly, to calculate hours spent sleeping each week, hours per night reported is multiplied by seven. For this study, total hours per week engaged in academic (items $a+b$ ), nonacademic (sum items $c$ to $h$ ), work for pay (item c), social (items $d+e)$, leisure (item $\mathrm{f}$ ), and health (items $\mathrm{g}+\mathrm{h}$ after multiplying, accordingly) were calculated. Our sample reported spending an average of 27.03 hours on academic activities $(\mathrm{SD}=$ 9.45, range 0 to 50 hours) and 80.82 hours on nonacademic activities ( $\mathrm{SD}=16.83$, range 43 to 132 hours) per week.

\section{RESULTS}

All statistical analyses were completed using Statistica 13 software. Missing data for the inventories were minimal and replaced using participants' mean value based on their responses to other items on that specific scale. Missing data were not replaced for self-reported grades, cumulative grades, credits, perceived balance, commitment to completing one's degree, hours spent per week engaging in various academic and nonacademic activities or for one case, where the University Adaptation Questionnaire and, for another case, the student satisfaction survey was not completed. The means and standard deviations for the well-developed scales were congruent with previous studies (see table 1), as were the bivariate correlations (e.g., Kennett \& Keefer, 2006; Reed \& Kennett 2017; see tables 3-5). Demographic factors, such as age, sex, university course credits attained were not significantly associated with any of the variables assessed and were not entered in the subsequent multivariate analyses. 
Table 1. Means and standard deviations of the variables

\begin{tabular}{lcccc}
\hline & $N$ & Mean & SD & RANGE \\
\hline SCS & 239 & 16.58 & 25.09 & $-68-78$ \\
ARI & 239 & 111.63 & 19.67 & $48-156$ \\
ASES & 239 & 39.33 & 8.32 & $12-54$ \\
UAQ & 238 & 73.06 & 16.58 & $24-108$ \\
SSS & 238 & 72.32 & 12.68 & $27-95$ \\
COMMIT & 214 & 6.45 & 1.03 & $1-7$ \\
ACAHR & 239 & 27.03 & 9.45 & $0-50$ \\
NONACHR & 232 & 80.82 & 16.83 & $43-132$ \\
WORKHR & 238 & 5.71 & 8.43 & $0-25$ \\
SOCHR & 238 & 9.45 & 7.23 & $0-35$ \\
LEISHR & 238 & 12.92 & 7.20 & $0-25$ \\
HEALHR & 235 & 52.72 & 9.89 & $16-85$ \\
BALANCE & 239 & 2.91 & 0.87 & $1-5$ \\
FGPA & 237 & 8.24 & 2.10 & $0-12$ \\
EGPA & 235 & 75.06 & 1.62 & $2-12$ \\
GRADE & 231 & 8.45 & 3.27 & $0.5-20$ \\
CREDIITS & 231 & & 87 & 0.86 \\
\hline
\end{tabular}

Key: SCS = Self-Control Schedule, ARI = Academic Resourcefulness Inventory, ASES = Academic Self-Efficacy Scale, UAQ = University Adaptation Questionnaire, SSS = Student Satisfaction Scale, COMMIT = commitment to completing degree, ACAHR = hours engaged in academic activities, NONACHR $=$ hours engaged in non-academic activities, WORKHR $=$ hours engaged in work activities, SOCHR $=$ hours engaged in social activities, LEISHR = hours engaged in leisure activities, HEALHR = hours engaged in health activities, BALANCE = perceived balance, FGPA = fall 2016 grade point average, and EGPA = expected grade point average for April 2017.

As shown in table 1, on average students engaged in approximately 27 hours of academic and 81 hours of nonacademic related activities weekly, with slightly more than half of the nonacademic hours consisting of sleep $(M=7.15$ hours each night). Sleep quality was unrelated to grades $(r=.12)$, as was hours of sleep per night $(r=-.01)$. Table 2 , however, illustrates that students engaging in greater academic-related activities were more likely to attain higher grades as well as to report attaining and expecting higher grades, perceive better academic/nonacademic balance, and be more academically efficacious, adjusted to university life, committed to completing their degree, and generally and academically resourceful. Conversely, total hours per week spent in nonacademic-related activities was associated weakly with only perceptions of balance $(\mathrm{r}=.14)$ and student satisfaction $(\mathrm{r}=.15)$. Nonetheless, additional weak to moderate correlations were observed between hours spent per week in nonacademic related activities and some of the psychosocial variables, particularly social and leisure activities, with social activities being positively and leisure activities being negatively related to particular variables (see table 2). 
Table 2. Bivariate correlations between hours spent in academic and nonacademic activities and the psychosocial and outcome variables

\begin{tabular}{|c|c|c|c|c|c|c|}
\hline & ACAHR & NONACAHR & WORKHR & SOCHR & LEISHR & HEALHR \\
\hline SCS & $.19^{* *}$ & .10 & $.16^{*}$ & $.18^{* *}$ & $-.20^{* *}$ & .05 \\
\hline ARI & $.37^{* * *}$ & .07 & 12 & $.21^{* * *}$ & $-.28^{* * *}$ & .07 \\
\hline ASES & $.24^{* * *}$ & .10 & $.13^{*}$ & .10 & $-.15^{*}$ & .10 \\
\hline UAQ & $.22^{* * *}$ & .08 & -.02 & $.20^{* *}$ & -.12 & .07 \\
\hline SSS & .05 & $.15^{*}$ & -.02 & .10 & .03 & $.18^{* *}$ \\
\hline COMMIT & $.21^{* *}$ & .07 & .09 & .04 & -.06 & .04 \\
\hline BALANCE & $.20^{* *}$ & $.14^{*}$ & .09 & $.23^{* * *}$ & $-.15^{*}$ & .11 \\
\hline FGPA & $.30^{* * *}$ & .08 & .10 & .09 & $-.14^{*}$ & .09 \\
\hline EGPA & $.32^{* * *}$ & .06 & .05 & .13 & $-.18^{* *}$ & .09 \\
\hline GRADE & $.31^{* * *}$ & -.02 & .06 & .01 & -.13 & -.01 \\
\hline CREDITS & .03 & .04 & .11 & .02 & .03 & -.06 \\
\hline
\end{tabular}

Key: SCS = Self-Control Schedule, ARI = Academic Resourcefulness Inventory, ASES = Academic Self-Efficacy Scale, UAQ = University Adaptation Questionnaire, SSS = Student Satisfaction Scale, COMMIT = commitment to completing degree, ACAHR = hours engaged in academic activities, NONACHR = hours engaged in nonacademic activities, WORKHR = hours engaged in work activities, $\mathrm{SOCHR}=$ hours engaged in social activities, LEISHR = hours engaged in leisure activities, HEALHR = hours engaged in health activities, BALANCE = perceived balance, FGPA = fall 2016 grade point average, and EGPA = expected grade point average for April 2017.

$N=208$ to 239

Notes: ${ }^{*} p<.05,{ }^{* *} p<.01,{ }^{* * *} p<.001$

Based on literature showing the benefits of moderate employment, students were categorized as working between 11 and 20 hours versus working fewer or more hours. An independent t-test revealed no significant differences between the two groups in grades, $\mathrm{t}(228)=1.33, p=.19$. This value remained nonsignificant even when controlling for full-time/part-time enrolment status, $F(1,227)=1.60, p=.21$. Few students $(N=36)$, however, reported working between 11 and 20 hours per week. Also, working more than 20 hours per week was unrelated to commitment to complete one's degree, $\mathrm{t}(211)=-0.86, p$ $=.39$, and grades, $\mathrm{t}(228)=-0.08, p=.93$.

Three standard multiple regression analyses were run to determine the unique/direct predictors of academic resourcefulness, university adaptation, and grades, separately, as the dependent variables. Only variables that were significantly related to the dependent variable at the bivariate level were included in each analysis. Independent variables in standard regression are entered simultaneous, with the significant semi-partial correlation coefficients $(s r)$ indicating the independent variables making a direct contribution to the dependent variable and its squared value providing the amount of unique variance being accounted for in the relationship. In all instances, the assumptions of independence, normality, linearity, and homoscedasticity were met. There was no incidence of multicollinearity (i.e., variation inflation factors levels were well below the recommended value of 5; see Rogerson, 2001) or suppressor effects (i.e., none of semi-partial correlations increased in size or changed direction, when controlling for the other independent variables). 
As shown in table 3, greater perceptions of balance, general resourcefulness, academic selfefficacy, and academic and social hours, and fewer leisure hours were related to higher academic resourcefulness scores, at the bivariate level. These variables accounted for 52 percent of the total variance, with all the variables except for social hours making a direct contribution to the prediction of academic resourcefulness, accounting for 23 percent of the unique variance. A substantial amount of the variance, however, was shared among all of the variables (29 percent). In summary, students who were more academically resourceful were more likely to spend more hours engaging in academic activities and less time in leisure endeavors, be more generally resourceful and academically self-efficacious, and have greater perceptions of their ability to balance academic and nonacademic tasks.

Table 3. Summary of standard multiple regression for academic resourcefulness: ARI (y) with general resourcefulness (SCS), academic self-efficacy (ASES), perceived balance, academic hours, social hours, and leisure hours as independent variables $(N=237)$

\begin{tabular}{|c|c|c|c|c|c|c|}
\hline VARIABLE & $r$ & $b$ & SE & $\beta$ & $s r$ & $s r^{2}$ \\
\hline $\begin{array}{l}\text { GENERAL } \\
\text { RESOURCECFULNESS }\end{array}$ & $.46^{* * *}$ & $.14^{* * *}$ & .04 & $.18^{* * *}$ & $.16^{* * *}$ & $.03^{* * *}$ \\
\hline SELF-EFFICACY & $.52^{* * *}$ & $.68^{* * *}$ & .12 & $.29^{* * *}$ & $.26^{* * *}$ & $.07^{* * *}$ \\
\hline BALANCE & $.52^{* * *}$ & $6.83^{* * *}$ & 1.13 & $.30^{* * *}$ & $.28^{* * *}$ & $.08^{* * *}$ \\
\hline ACADEMIC HOURS & $.37^{* * *}$ & $.40^{* * *}$ & .10 & $.19^{* * *}$ & $.18^{* * *}$ & $.03^{* *}$ \\
\hline SOCIAL HOURS & $.21^{* *}$ & .21 & .13 & .08 & .07 & .00 \\
\hline LEISURE HOURS & $-.28^{* * *}$ & $-.42^{* *}$ & .13 & $-.15^{* *}$ & $-.15^{* *}$ & $.02^{* *}$ \\
\hline \multirow[t]{3}{*}{ INTERCEPT } & & 55.31 & 5.67 & \\
\hline & & \multicolumn{2}{|c|}{$\boldsymbol{R}=. \mathbf{7 2} \mathbf{2}^{* * *}$} & Uniqu & bility $=$ & \\
\hline & & \multicolumn{2}{|c|}{$R^{2}=.52$} & \multicolumn{3}{|c|}{ Shared variability $=.29$} \\
\hline
\end{tabular}

Key: General resourcefulness $=$ general learned resourcefulness; self-efficacy $=$ academic self-efficacy; balance $=$ perceived balance; hours $=$ per week; $r=$ bivariate correlation; $b=$ unstandardized regression coefficient, $\mathrm{SE}=$ standard error; $B=$ beta/standardized coefficient; $s r$ $=$ semi-partial correlation; $s r^{2}=$ semi-partial correlation squared.

Notes: ${ }^{*} p<.05 .{ }^{* *} p<.01$. ${ }^{* * *} p<.001$.

University adaptation was positively associated at the bivariate level with perceived balance, general and academic resourcefulness, academic self-efficacy, and time spent engaging in academic and social activities. Standard multiple regression analysis revealed that perceived balance, and general and academic resourcefulness uniquely contributed to the prediction of university adaptation (unique variance $=7$ percent), with the total and shared variance being 26 percent and 19 percent, respectively (see table 4). Hence, students who were more adjusted at university were more likely to have higher perceived balance scores and be more generally and academically resourceful. 
Table 4. Summary of standard multiple regression for university adaptation: $U A Q(y)$ with general resourcefulness (SCS), academic resourcefulness (ARI), academic self-efficacy (ASES), perceived balance, academic hours, and social hours as independent variables $(N=237)$

\begin{tabular}{|c|c|c|c|c|c|c|}
\hline VARIABLE & $r$ & $b$ & SE & $\beta$ & $s r$ & $s r^{2}$ \\
\hline $\begin{array}{l}\text { GENERAL } \\
\text { RESOURCEFULNESS }\end{array}$ & $.37^{* * *}$ & $.12^{* *}$ & .04 & $.18^{* *}$ & $.16^{* *}$ & $.03^{* *}$ \\
\hline $\begin{array}{l}\text { ACADEMIC } \\
\text { RESOURCEFULNESS }\end{array}$ & $.43^{* * *}$ & $.15^{*}$ & .07 & $.18^{*}$ & $.13^{*}$ & $.02^{*}$ \\
\hline SELF-EFFICACY & $.30^{* * *}$ & .13 & .13 & .06 & .05 & .00 \\
\hline BALANCE & $.37^{* * *}$ & $3.40^{* *}$ & 1.27 & $.18^{* *}$ & $.15^{* *}$ & $.02^{* *}$ \\
\hline ACADEMIC HOURS & $.22^{* *}$ & .10 & .11 & .06 & .05 & .00 \\
\hline SOCIAL HOURS & $.20^{* *}$ & .18 & .13 & .08 & .08 & .01 \\
\hline INTERCEPT & & $\begin{array}{l}34.45 \\
R=.51 \\
R^{2}=.2 \\
\text { Adj. } R^{2}\end{array}$ & 6.32 & $\begin{array}{l}\text { variab } \\
\text { sariabi }\end{array}$ & & \\
\hline
\end{tabular}

Key: General resourcefulness $=$ general learned resourcefulness; academic resourcefulness $=$ academic resourcefulness; self-efficacy $=$ academic self-efficacy; balance $=$ perceived balance; hours $=$ per week; $r=$ bivariate correlation; $b=$ unstandardized regression coefficient, $\mathrm{SE}=$ standard error; $B=$ beta/standardized coefficient; $s r=$ semi-partial correlation; $s r^{2}=$ semi-partial correlation squared. Notes: ${ }^{*} p<.05 .{ }^{* *} p<.01 .{ }^{* * *} p<.001$.

Cumulative grades were positively associated with academic resourcefulness, academic selfefficacy, hours per week engaged in academic activities, and perceived balance, with these variables accounting for 23 percent of the variance. Academic resourcefulness and hours engaging in academic related activities played a direct role, accounting for 6 percent of the unique variance. Hence, students attaining higher grades were more likely to be engaging in academic resourceful behaviors and more hours in their academic studies (see table 5).

Table 5. Summary of standard multiple regression for grades ( $y$ ) with academic resourcefulness (ARI), academic selfefficacy (ASES), perceived balance, and academic hours as independent variables $(N=231)$

\begin{tabular}{lllllll}
\hline VARIABLE & $r$ & $b$ & SE & $\beta$ & $s r$ & $s r^{2}$ \\
\hline ACADEMIC & & & & & & \\
RESOURCEFULNESS & $.37^{* * *}$ & $.11^{* *}$ & .04 & .24 & $.17^{* *}$ & $.03^{* *}$ \\
SELF-EFFICACY & $.29^{* * *}$ & .12 & .08 & .11 & .10 & .01 \\
BALANCE & $.19^{* *}$ & -.02 & .72 & -.00 & -.00 & .00 \\
ACADEMIC HOURS & $.31^{* * *}$ & $.18^{* *}$ & .06 & $.19^{* *}$ & $.18^{* *}$ & $.03^{*}$ \\
INTERCEPT & 53.30 & 3.27 & & \\
& $R=.48^{* * *}$ & Unique variability $=.06$ & \\
& $R^{2}=.23$ & Shared variability $=.17$ \\
& $A d j . R^{2}=.21$ & & \\
& & &
\end{tabular}

Key: Academic resourcefulness $=$ academic resourcefulness; self-efficacy $=$ academic self-efficacy; balance $=$ perceived balance; hours $=$ per week; $r=$ bivariate correlation; $b=$ unstandardized regression coefficient, $S E=$ standard error; $B=$ beta/standardized coefficient; $s r=$ semi-partial correlation; $\mathrm{sr}^{2}=$ semi-partial correlation squared.

Notes: ${ }^{*} p<.05 .{ }^{* *} p<.01 .{ }^{* * *} p<.001$. 
To determine whether the relationship between perceived balance (BAL, independent variable) and hours spent engaging in academic endeavors (ACADHRS, dependent variable) changes as a function of academic resourcefulness (ART, the moderator), a moderating analysis was conducted. To circumvent multicollinearity and evaluate how the interaction between balance perception and academic resourcefulness influences engagement in academic hours, perceived balance and academic resourcefulness were first centered as recommended by Howell (2013). At step 1, centered balance (BAL) and academic resourcefulness scores (ARI) were entered and these main effects accounted for 14 percent of the total variance in academic hours per week (ACADHRS), with academic resourcefulness uniquely contributing 10 percent of the variance to the prediction $(p<.001)$. The main effect of perceived balance did not reach significance $(p=.92)$, with its contribution being shared with academic resourcefulness ( 14 percent -10 percent $=4$ percent $)$. The product of perceived balance and academic resourcefulness (the interaction) was entered at step 2, and significantly accounted for an additional 2 percent of the variance to the prediction of academic hours per week $(p=.02)$. Based on the regression coefficients and intercept at step 2, ACADHRS $=.34(\mathrm{BAL})+.16(\mathrm{ART})+[-.063$ Moderator + 27.58], two linear regression lines were computed (see Howell, 2013), one for low academic resourcefulness $(\mathrm{ACADHRS}=2.86(\mathrm{BAL})+21.18)$ and one for high academic resourcefulness $(\mathrm{ACADHRS}=-2.18$ $(\mathrm{BAL})+33.98)$. Low and high BAL scores and ART scores were considered as 2 standard deviations below and above the mean. As signified by the slopes of the two equations (see figure 1), the relationship between balance and academic hours was positive for low academic resourcefulness and negative for high academic resourcefulness. Shown in figure 1, students scoring low in balance and low in academic resourcefulness engaged in the fewest academic hours per week (i.e., 16.2 hours), whereas students scoring high in balance and low in academic resourcefulness engaged in considerably more academic hours per week (26.2 hours). The negative relationship between balance and academic hours for high academic resourcefulness had predicted scores for academic hours above the two values described for the low academic resourcefulness function (see figure 1). Students engaging in the most academic hours (i.e., 37.8 hours per week) were those having low perceptions of balance and high academic resourcefulness scores.

Figure 1. The moderating role of academic resourcefulness (ARI) in the relationship between perceived balance and academic hours per week, with low and high ARI and perceived balance being 2 standard deviations below and above the mean

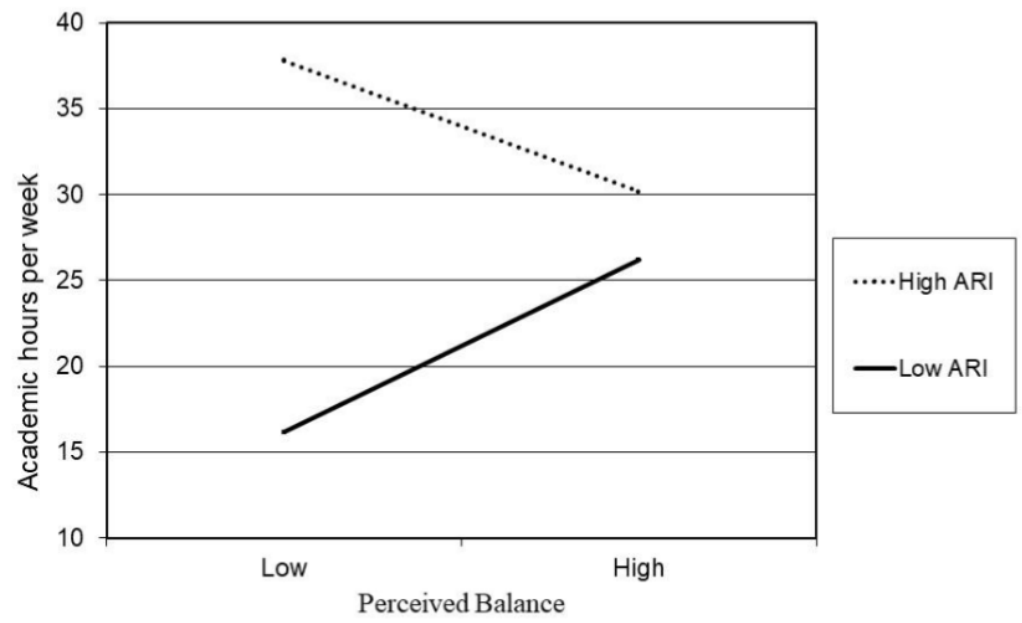

146 Kennett, D. J., Reed, M. J., \& VandenBerg, T. R. (2019). The importance of perceived university-life balance, hours per week engaged in academic activities, and academic resourcefulness. Teaching \& Learning Inquiry, 7(1). http://dx.doi.org/10.20343/teachlearninqu.7.1.9 
In light of the findings illustrated by figure 1, it was important to determine whether high perceptions of balance and/or engagement in high levels of academic hours were associated with similar grades for students scoring low and high in academic resourcefulness. Hence, two additional moderating analyses were performed. In the first analysis assessing if academic resourcefulness moderated the relationship between perceived balance (BAL, independent variable) and grades (dependent variable), centered balance (BAL) and academic resourcefulness scores (ARI) were entered at step 1 and these main effects accounted for 15 percent of the total variance in grades, with academic resourcefulness uniquely contributing 12 percent of the variance to the prediction $(p<.001)$. The main effect of perceived balance did not reach significance $(p=.69)$, with its contribution being shared with academic resourcefulness ( 15 percent -12 percent $=3$ percent $)$. The product of perceived balance and academic resourcefulness (the interaction) was entered at step 2 , and did not significantly predict grades ( $p=.30)$, with the nonsignificant interaction shown in figure 2. In summary, students scoring higher in academic resourcefulness achieved higher cumulative grades compared to their low resourceful counterparts, regardless of their level of balance.

Similarly, after entering centered academic hours per week (ACAHR-IV) and academic resourcefulness scores (ARI-moderator) at step 1, which accounted for 17.5 percent of the variance in grades (with ACAHR and ARI accounting for 3.5 percent and 7.8 percent of unique variance, respectively), entering the product of academic hours and academic resourcefulness (the interaction) failed to reach significance $(p=.27)$. The non-significant interaction is shown in figure 3. In summary, students scoring higher in academic resourcefulness achieved higher cumulative grades than their low resourceful counterparts, regardless of the hours they dedicated to their studies each week.

Figure 2. The moderating role of academic resourcefulness (ARI) in the relationship between perceived balance and grades, with low and high ARI and perceived balance being 2 standard deviations below and above the mean

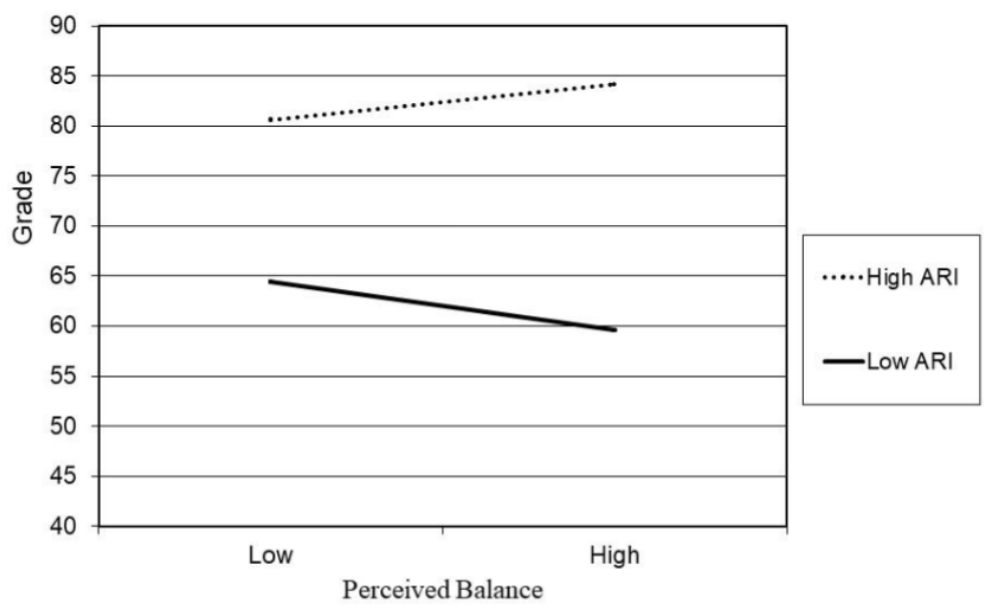


Figure 3. The moderating role of academic resourcefulness (ARI) in the relationship between academic hours per week and grades, with low and high ARI and academic hours being 2 standard deviations below and above the mean

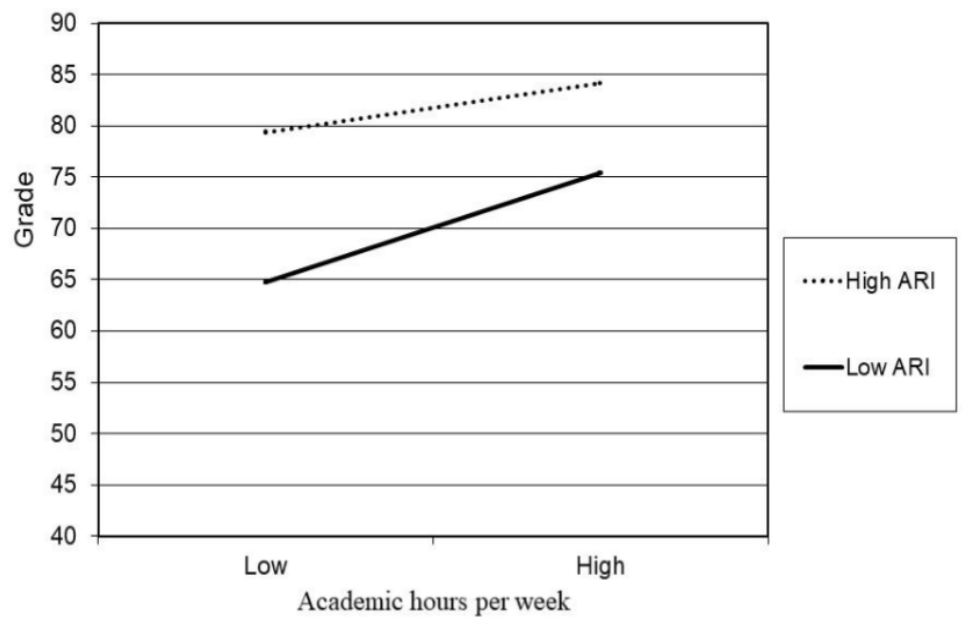

\section{DISCUSSION}

An aim of the current investigation was to determine if students' perceptions of balance between academic and nonacademic activities were associated with the hours they dedicate each week to these endeavors and if these hours were uniquely related to academic resourcefulness, performance, and university adaptation. Bivariate correlations revealed that the total number of hours per week spent engaging in nonacademic activities were mostly unrelated to the psychosocial and outcome variables examined here. Although the average number of 7.2 hours spent sleeping each night was consistent with other studies (Forquer, Camden, Gabriau, \& Johnson, 2008; Gilbert \& Weaver, 2010; Lund, Reider, Whiting, \& Prichard, 2010), hours of sleep and sleep quality were unrelated to grades. Further, in contrast to Dundes and Marx (2006), being employed 11 to 20 hours per week was not associated with higher grades and, in contrast to Hovdhaugen (2015), being employed more than 20 hours was not associated with higher dropout rates, although our study assessed commitment to completing one's degree and not actual degree completion, as Hoydhaugen did. Moreover, engagement in more social activities was unrelated to university satisfaction noted by Stuart et al. (2011) and Strapp and Farr (2009). However, in partial support of Anand (2007) who observed that students spending more hours playing video games was associated with lower grades, we found that students engaging in more hours per week in leisure activities were more likely to report receiving lower fall semester grades and lower expected grades for the winter term, though these correlations were weak in value and leisure hours were unrelated to actual grades. Nevertheless, as expected, the number of hours per week engaging in academic activities were positively associated with self-reported grades, cumulative grades, perceptions of balance, general and academic resourcefulness, academic self-efficacy, university adaptation, and commitment to completing one's degree.

Noteworthy, the findings were in line with other investigations, showing that higher levels of perceived balance, general resourcefulness skills, and academic self-efficacy were unique predictors of academic resourcefulness (e.g., Kennett, 1994, Kennett \& Keefer, 2006; Reed \& Kennett, 2017). Contributing further to the unique prediction of academic resourcefulness, we found that more hours 
engaged in academic tasks and less hours engaged in leisure tasks were important to this relationship. Furthermore, the unique and positive predictors of grades were academic resourcefulness and hours engaged in academic activities, with higher academic self-efficacy and perceived balance scores making a shared contribution. Past studies, where hours engaged in academic tasks and perceived balance were not measured, have consistently found academic resourcefulness and academic self-efficacy to have a direct influence on grades (Kennett, 1994; Kennett \& Keefer, 2006; Martin \& Kennett, 2017). The findings together here highlight the value of students spending more hours in academic-related activities and being academic resourcefulness, with both variables having a positive impact on grades.

Supporting another hypothesis of the current investigation, the relationship between perceived balance and actual hours spent engaging in academic endeavors was observed to change as a function of academic resourcefulness. Students scoring low in academic resourcefulness and having high perceived balance endorsed spending substantially more hours per week engaged in academic activities compared to their low resourceful counterparts having low balance perceptions. This finding is intriguing, especially given the consistently reported finding that students scoring low in resourcefulness generally do not do well academically (e.g., Kennett, 1994; Kennett \& Keefer, 2006; Martin \& Kennett, 2017). Perhaps when engaging in academic activities, this group of students are often off task, reading poorly, and/or employing study methods that do not work well in higher education, with these hours falsely contributing towards their high perception of balance, but not toward high grades. In support of this notion, two further moderating analyses showed that, for students scoring low in resourcefulness, regardless of having high balance perceptions or dedicating a high number of hours per week to their studies, their cumulative grades were markedly lower than students scoring high in resourcefulness. Conversely, students scoring high in resourcefulness engaged in the highest academic hours per week. Given the self-regulatory nature of the construct academic resourcefulness itself, more highly academically resourceful students are likely spending far more "quality" versus "wasted" hours on academic endeavors, explaining why their grades were observed to be much better than low resourceful students in our and other studies (e.g., Kennett, 1994; Kennett \& Keefer, 2006; Kennett \& Reed, 2009; Martin \& Kennett, 2017).

The moderating analysis illustrated in figure 1 also showed that the relationship between perceived balance and academic hours per week for students high in academic resourcefulness was negative. A reason why low perceived balance was associated with the greatest academic hours per week for those high in academic resourceful conceivably could be that their perceptions of low balance was based on spending too much time on academic compared to nonacademic endeavors and is worth further exploration in subsequent research. Unfortunately, the perceived balance item did not have a follow-up question asking if low perceptions of balance were based on engaging in too many academic versus nonacademic tasks or vice-versa. Subsequent studies interested in balance perceptions, for example, could ask students to rate perceived balance along a continuum, whereby at one end of this continuum is spending an excessive amount of time on nonacademic tasks and at the other end is spending an excessive amount of time on academic tasks, with middle of this continuum being a balance of the two types of activities.

The observation that academic resourcefulness and more engagement in academic activities were associated with higher cumulative grades reinforces the value of institutions offering selfmanagement/academic success courses. Such curricula have been found effective at teaching academic 
resourcefulness strategies, with significant improvements observed in academic resourcefulness and grades for students completing the sessions, illustrating that these skills can be learned (Kennett, 1994; Kennett \& Reed, 2009; Reed et al., 2009; Reed, Kennett, Lewis, \& Lund-Lucas, 2011.) Moreover, engaging in greater academic self-regulation and attaining higher grades would hopefully allow students to recognize the importance of putting in the hours in the pursuit of academic success.

Supporting previous investigations (Kennett \& Keefer; Martin \& Kennett, 2017; Reed \& Kennett, 2017), students having higher perceptions of academic/nonacademic balance, being more generally and academically resourceful were more likely to be adapted to the university environment such that they felt at home, were making friends, and were enjoying the academic experience. Not surprisingly, hours per week engaged in social and academic activities contributed to the prediction of adaptation in a shared manner.

The main limitation of this study is its generalizability to other undergraduate students. Our sample was predominantly female and Caucasian, and from a small, liberal arts university in Ontario, Canada. The extent to which our findings apply to male students, undergraduates belonging to a different ethnic or cultural group, and students from larger universities or ones offering a different selection of programs remains to be determined. Additionally, the perceived balance item does not assess whether the ability to balance academic and nonacademic activities is offset because of engaging in too many academic or nonacademic activities. Based on past studies finding that more highly academically resourceful students are less incline to attribute academic disappointments to lack of effort or personal ability (Kennett \& Keefer, 2006; Martin \& Kennett, 2017), we suspect that students scoring high in academic resourcefulness and having low perceptions of balance are sacrificing nonacademic activities for academic ones, with the converse to be the case for those scoring low in academic resourcefulness. Finally, the university life experience inventory limits the number of hours a student can select for each activity. For example, it is very plausible for an athlete to be engaging in more than the set cut-off of 7 hours of physical activity in a week, as well as for a nursing student to be engaging in more than the set cut-off of 25 hours of academic class/placements and for any person to be engaging in more than the set cut-off of 25 hours of leisure, social, and academic preparation activities. Notable, a limited percentage of students were in this cut-off category for these activities, ranging from 1.7 percent for social activities both in the community and university to 13 percent for leisure activities.

In summary, the number of hours spent per week in academic activities was positively associated with general resourcefulness, academic self-efficacy, university adjustment, and degree completion and a unique predictor of academic resourcefulness and cumulative grades. Moreover, academic resourcefulness was observed to moderate the relationship between perceived ability to balance academic and nonacademic activities and academic hours, such that the average number of hours spent engaged in academic activities per week was greater for students scoring high in academic resourcefulness regardless of whether they had low or high perceptions of balance, especially compared to those students who scored low in both academic resourcefulness and perceived balance. These findings have implications for practice when dealing with students at risk of failing. Academic counselors may find teaching students how to become more academically resourceful will help them to increase the number of hours they dedicate to their academic studies each week and, in turn, enhance low perceptions of balance. Our findings further support that telling students scoring low in resourcefulness to increase study time is not enough without guiding them on what to do in that time. Thus, providing 
these students with methods on how to cope with academic challenges and setbacks, along with effective study skills training, is important.

In conclusion, the time spent on academic activity was associated with higher grades and better adjustment, but these relationships were dependent on students' academic resourcefulness. Such findings suggest that being highly academically resourceful allows students to remain on task and engage in study behaviors that lead to success. Teaching students who score low in academic resourcefulness on how to effectively manage their academic studies is important regardless of their balance perceptions.

Deborah J. Kennett is Professor Emeritus at Trent University (CAN). Her research focuses on academic self-regulation with special emphasis on program development, and on the personal and social factors influencing academic success and university adjustment.

Maureen J. Reed is Full Professor at Ryerson University (CAN). Her research interests include access to education for students with disabilities, higher education success, and experiences of first-generation students, student resilience, and resourcefulness.

Tasmine R. VanderBerg completed this research in partial fulfillment of her Bachelor of Science degree in psychology at Trent University (CAN).

\section{REFERENCES}

American College Health Association. (2016). A College Health Association-National College Health Assessment Il: Undergraduates student reference group. Executive summary spring 2016. Hanover, MD: American College Health Association. Retrieved from https://www.acha.org/documents/ncha/NCHAII\%20SPRING\%202016\%20CANADIAN\%20REFERENCE\%20GROUP\%20EXECUTIVE\%20SUMMARY.pdf

Anand, V. (2007). A study of time management: The correlation between video game usage and academic performance markers. CyberPsychology \& Behavior, 10(4), 552-559. https://doi.org/10.1089/cpb.2007.9991

Boonpongmanee, C., Zauszniewski, J. A., \& Boonpongmanee, S. (2002). Psychometric properties of the selfcontrol schedule: Thai version. Research in Nursing and Health, 25, 471-478. https://doi.org/10.1002/nur.10058

Bergen-Cico, D., \& Viscomi, J. (2012). Exploring the association between campus co-curricular involvement and academic achievement. Journal of College Student Retention: Research, Theory \& Practice, 14(3), 329-343. https://doi.org/10.2190/CS.14.3.c

Buote, V., Pancer, S., Pratt, M., Adams, G., Birnie-Lefcovitch, S., Polivy, J., \& Wintre, M. (2007). The importance of friends. Journal of Adolescent Research, 22(6), 665-689. https://doi.org/10.1177/0743558407306344

Crombag, H. F. M. (1968). Studiemotivatie en studieattitude: een onderzoek naar de invloed van verenigingslidmaatschap op studiemotivatie en studieattitude, en de rol die deze. Groningen: Wolters.

Dundes, L., \& Marx, J. (2006). Balancing work and academics in college: Why do students working 10 to 19 hours per week excel? Journal of College Student Retention: Research, Theory \& Practice, 8(1), 107-120. https://doi.org/10.2190/7UCU-8F9M-94QG-5WWQ

Forquer, L. M., Camden, A. E., Gabriau, K. M., \& Johnson, C. M. (2008). Sleep patterns of college students at a public university. Journal of American College Health, 56(5), 563-565. https://doi.org/10.3200/JACH.56.5.563-565

Galbraith, C. S., \& Merrill, G. B. (2015). Academic performance and burnout: An efficient frontier analysis of resource use efficiency among employed university students. Journal of further and Higher Education, 39(2), 255-277.https://doi.org/10.1080/0309877X.2013.858673

Gilbert, S. P., \& Weaver, C. C. (2010). Sleep quality and academic performance in university students: A wake-up call for college psychologists. Journal of College Student Psychotherapy, 24(4), 295-306. https://doi.org/10.1080/87568225.2010.509245

Holmes, V. (2008). Working to live: Why university students balance full-time study and employment. Education+ Training, 50(4), 305-314.https://doi.org/10.1108/00400910810880542 
Hovdhaugen, E. (2015). Working while studying: The impact of term-time employment on dropout rates. Journal of Education and Work, 28(6), 631-651. https://doi.org/10.1080/13639080.2013.869311

Howell, D. C. (2013). Statistical methods for psychology (8th ed.). Belmont, CA: Wadsworth, Cengage Learning.

Kennett, D. J. (1994). Academic self-management counselling: Preliminary evidence for the importance of learned resourcefulness on program success. Studies in Higher Education, 19(3), 295-307. https://doi.org/10.1080/03075079412331381890

Kennett, D. J., \& Keefer, K. (2006). Impact of learned resourcefulness and theories of intelligence on academic achievement of university students: An integrated approach. Educational Psychology, 26(3), 441-457. https://doi.org/10.1080/01443410500342062

Kennett, D. J., \& Reed, M. J. (2009). Factors influencing academic success and retention following a 1st-year postsecondary success course. Educational Research and Evaluation, 15(2), 153166. https://doi.org/10.1080/13803610902804382

Lowe, J., \& Gayle, V. (2007). Exploring the work/life/study balance: The experience of higher education students in a Scottish further education college. Journal of Further and Higher Education, 31(3), 225-238. https://doi.org/10.1080/03098770701424942

Lund, H. G., Reider, B. D., Whiting, A. B., \& Prichard, J. R. (2010). Sleep patterns and predictors of disturbed sleep in a large population of college students. Journal of Adolescent Health, 46(2), 124-132. https://doi.org/10.1016/j.jadohealth.2009.06.016

Martin, R. D., \& Kennett, D. J. (2017). To be kind or not to be kind: The moderating role of self-compassion in the relationship between general resourcefulness and academic self-regulation. Journal of Social Psychology, 158(5): 626-638. https://doi.org/10.1080/00224545.2017.1407286

Mokhtari, K., Reichard, C. A., \& Gardner, A. (2009). The impact of internet and television use on the reading habits and practices of college students. Journal of Adolescent \& Adult Literacy, 52(7), 609-619. https://doi.org/10.1598/JAAL.52.7.6

Neill J. (2004). The University Student Motivation and Satisfaction Questionnaire version 2. (TUSMSQ2), Centre for Applied Psychology, University of Canberra.

Ngai, F., Chan, S. W., \& Holroyd, E. (2008). Translation and validation of a Chinese version of the self-control schedule in Chinese childbearing women. Journal of Clinical Nursing, 17, 323-332. http://dx.doi.org/10.1111/j.1365-2702.2006.01882.x

Reed, M. J., \& Kennett, D. J. (2017). The importance of university students' perceived ability to balance multiple roles: a comparison of students with and without disabilities. Canadian Journal of Higher Education, 47(2) 71-86. http://journals.sfu.ca/cjhe/index.php/cjhe/article/view/187965

Reed, M. J., Kennett, D. J., Lewis, T., \& Lund-Lucas, E. (2011). The relative benefits found for students with and without learning disabilities taking a first-year university preparation course. Active Learning in Higher Education, 12(2), 133-142.https://doi.org/10.1177/1469787411402483

Reed, M. J., Kennett, D. J., Lewis, T., Lund-Lucas, E., Stallberg, C., \& Newbold, I. L. (2009). The relative effects of university success courses and individualized interventions for students with learning disabilities. Higher Education Research and Development, 28(4), 385-400.https://doi.org/10.1080/07294360903067013

Redden, E. M., Tucker, R. K., \& Leslie, Y. (1983). Psychometric properties of the Rosenbaum schedule for assessing self-control. Psychological Record, 33, 77-86. https://doi.org/10.1007/BF03394824

Rogerson, P.A. (2001). Statistical methods for geography. London, UK: Sage.

Rosenbaum, M. (1980). A schedule for assessing self-control behaviors: Preliminary findings. Behavior therapy, 11(1), 109-121.https://doi.org/10.1016/S0005-7894(80)80040-2

Rosenbaum, M. E. (1990). Learned resourcefulness: On coping skills, self-control, and adaptive behavior. New York, NY: Springer.

Strapp, C. M., \& Farr, R. J. (2009). To get involved or not: The relation among extracurricular involvement, satisfaction, and academic achievement. Teaching of Psychology, 37(1), 50-54. https://doi.org/10.1080/00986280903425870

Stuart, M., Lido, C., Morgan, J., Solomon, L., \& May, S. (2011). The impact of engagement with extracurricular activities on the student experience and graduate outcomes for widening participation populations. Active Learning in Higher Education, 12(3), 203-215. https://doi.org/10.1177/1469787411415081

Van Rooijen, L. (1986). Advanced students' adaptation to college. Higher Education, 15(3/4), 197-209. https://doi.org/10.1007/BF00129211

152 Kennett, D. J., Reed, M. J., \& VandenBerg, T. R. (2019). The importance of perceived university-life balance, hours per week engaged in academic activities, and academic resourcefulness. Teaching \& Learning Inquiry, 7(1). http://dx.doi.org/10.20343/teachlearninqu.7.1.9 
Xuereb, S. (2015). Academic resourcefulness, coping strategies and doubting in university undergraduates. Journal of further and Higher Education, 39(2), 205-222. https://doi.org/10.1080/0309877X.2013.817004

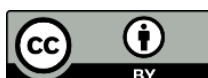

Copyright for the content of articles published in Teaching \& Learning Inquiry resides with the authors, and copyright for the publication layout resides with the journal. These copyright holders have agreed that this article should be available on open access under a Creative Commons Attribution License 4.0 International (https://creativecommons.org/licenses/by/4.0). The only constraint on reproduction and distribution, and the only role for copyright in this domain, should be to give authors control over the integrity of their work and the right to be properly acknowledged and cited, and to cite Teaching \& Learning Inquiry as the original place of publication. Readers are free to share these materials-as long as appropriate credit is given, a link to the license is provided, and any changes are indicated. 